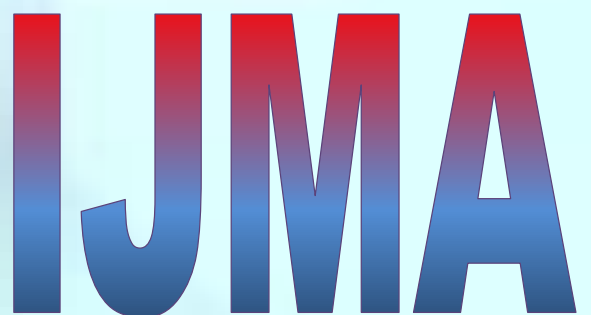

INTERNATIONAL

Journal of MEdical

\section{ARTS}

Volume 3, Issue 1 (Winter 2021)

http://ijma.journals.ekb.eg/

Print ISSN: 2636-4174

Online ISSN: 2682-3780

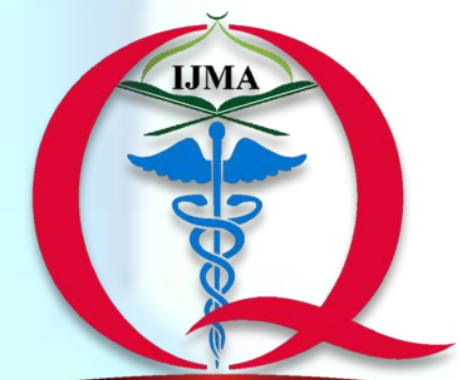

International Jounnal of Medical Arts

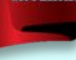




\section{About IJMA}

- International Journal of Medical Arts is the Official Journal of the Damietta Faculty of Medicine, Al-Azhar University, Egypt

- The First Issue was published in July 2019

- It is an International, Open Access, Double-blind, Peerreviewed Journal

- Published four times a year

- Published under the following license: Creative Commons Attribution-ShareAlike 4.0 International Public License (CC BY-SA 4.0). It had updated from the Creative Commons license [CC BY] in volume 2, Issue 4, October 2020

- The Egyptian Knowledge Bank hosts the web site of IJMA

- The Egyptian Knowledge Bank supports IJMA

- IJMA is indexed in the "Directory of Open Access Journals" Indexed on 15 January 2021.

- IJMA follows the regulations of the International Committee of Medical Journal Editors (list date 1/21/20)

- IJMA is a member of The International Society of Managing and Technical Editors

- IJMA is listed in Index Copernicus

- IJMA is listed in Publons, as EKB is an official partner with Clarivate Analytics
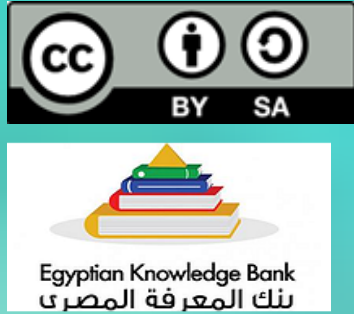

\section{DOAJ}

CMNE

ISMTE

INDEX COPERNICUS

publons 
International Journal of Medical Arts 2021; 3 [1]: 1075-1082.

Available online at Journal Website
https://ijma.journals.ekb.eg/
Main subject [Pediatrics]

Original article

\title{
Relation between Iron Status and Hemoglobin A1c in Children with Type-1 Diabetes Mellitus
}

\author{
Fatma Mustafa El Nezely[1]; Hussien Metwally Abd Elmaksoud[1]; Magdy Zaki El Ghanam[3]
}

Department of Pediatrics, Damietta Faculty of Medicine, Al-Azhar University, Egypt[1].

Department of Clinical Pathology, Damietta Faculty of Medicine, Al-Azhar University, Egypt[2]

Corresponding author: Fatma Mustafa El Nezely

Email: fatmaelnezely64@gmail.com

Received at: October 17, 2020; Revised at: November 18, 2020; Accepted at: November 18, 2020

DOI: 10.21608/ijma.2020.46734.1193

\section{ABSTRACT}

Background: Hemoglobin $\mathrm{A} 1 \mathrm{c}[\mathrm{HbA} 1 \mathrm{c}]$ is the best standard for measurements of glycemic control level in type 1 diabetes mellitus, especially in children. As iron deficiency anemia is a prevalent finding in children with diabetes, it may affect $\mathrm{HbA} 1 \mathrm{c}$ levels in those children.

Aim of the work: To determine the effects of iron deficiency anemia on hemoglobin A1c in type 1 diabetes mellitus

Patients and methods: This was cross-sectional analytic study was done on 80 children with diabetes with type 1DM receiving insulin therapy; the patients divided into two groups, 21 diabetic children with iron deficiency anemia and 59 diabetic children with iron sufficient state, attending to the pediatric department of Al-Azher University Hospital in Damietta from February 2019 to September 2019. All children included were subjected to complete medical history, general examination, systemic examination, and laboratory investigations; [Complete blood count [CBC], HbA1c, Serum Iron, Serum Ferritin, Total Iron Binding Capacity, Fasting blood glucose, Post Prandial blood glucose, and ESR].

Results: In our study, we divided all patients [80 diabetic children] regarding glycemic control according to HbA1c value into three levels, the first level was optimal glycemic control level [HbA1c $<.6 \%$ ], the second level was suboptimal glycemic control [HbA1c $7.6-9.0 \%$ ] and the third level was poor glycemic control level $[\mathrm{HbA} 1 \mathrm{c}>9.0 \%]$, there was a statically highly significant increase in $\mathrm{HbA} 1 \mathrm{c}$ value of the iron-deficient diabetic group in compared to iron sufficient diabetic group at all levels of glycemic control.

Conclusion: Iron deficiency anemia seems to increase $\mathrm{HbA1c}$ value in diabetic children Type 1 , at the same degree of glycemia.

Keywords: Hemoglobin A1c [HbA1c]; Iron deficiency anemia; Type 1 Diabetes Mellitus [T1DM]

This is an open-access article registered under the Creative Commons, ShareAlike 4.0 International license [CC BY-SA 4.0] [https://creativecommons.org/licenses/by-sa/4.0/legalcode.

Please cite this article: El Nezely FM, Abd Elmaksoud HM, EI Ghanam MZ. Relation between Iron Status and Hemoglobin A1c in Children with Type-1 Diabetes Mellitus. IJMA 2021; 3[1]: 1075-1082. DOI: 10.21608/ijma.2020.46734.1193.

${ }^{*}$ Main subject and any subcategories have been classified according to the research topic. 


\section{INTRODUCTION}

Diabetes mellitus type 1 [T1DM] is a chronic disease in which there is the failure of the body to synthesize insulin due to autoimmune damage of the beta cells that present in the pancreas. The most prevalent type of diabetes in children is type 1 and dependence on insulin therapy for life[1].

T1DM is usually diagnosed in children as well as adolescents, patients mostly presenting by a triad of symptoms [i.e., polyuria, polyphagia, as well as polydipsia] with hyperglycemia[2].

T1DM affects multiple systems and causes morbidity and mortality, so the diagnosis of T1DM is must be early as possible to avoid complications ${ }^{[3]}$.

The International Expert Committee and American Diabetes Association [ADA] have advised using hemoglobin $\mathrm{A} 1 \mathrm{c}[\mathrm{HbA} 1 \mathrm{c}]$ to diagnose DM, so HbA1c is more suitable if compared to past methods, which need fasting more than 8 hours. In addition to its suitability, $\mathrm{HbA} 1 \mathrm{c}$ has better reproducibility as well as describes a chronic hyperglycemic level of patients more than fasting plasma glucose. However, HbA1c is impacted by a variety of factors as genetic, ethnicity, age, and multiple factors related to the disease can affect HbA1c values[4].

Hemoglobin A1[HbA1] has multiple fractions, $\mathrm{HbA1c}$ is the most abundant one of $\mathrm{HbA1}$, and $\mathrm{HbA1c}$ is produced by glycation of terminal valine present in the $\beta$-chain of hemoglobin. HbA1c is considered as an indicator for the patient's glycemic level over the previous eight to twelve weeks. $\mathrm{HbA1c}$ is commonly performed for screening of diabetes mellitus[5].

Hemoglobin A1c values may be affected by some diseases unrelated to diabetes mellitus as anemia[6].

Iron deficiency anemia [IDA] is the most common type of anemia in the world. IDA is commonly present in infancy and adolescents who have menstruation, but the risk of IDA is increased in any child with a high growth rate or their requirements are not met properly[7]. Hemoglobin, hematocrit, mean corpuscular volume [MCV], mean corpuscular hemoglobin [MCH] and mean corpuscular hemoglobin concentration [MCHC] were decreased in anemic patients to give a picture of microcytic hypochromic anemia that is mostly Iron deficiency anemia [8].

\section{AIM OF THE WORK}

This study aimed to determine the effects of iron deficiency anemia on hemoglobin A1c in type 1 diabetes mellitus.

\section{PATIENTS AND METHODS}

This was a cross-sectional analytic study which was done on 80 diabetic children with type $1 \mathrm{DM}$ receiving insulin therapy [ 43 girls and 37 boys] were included in the study. The children were divided into two groups, 21 diabetic children with iron deficiency anemia and 59 diabetic children with iron sufficient state, attending the pediatric department of Al-Azher University Hospital in Damietta from February 2019 to September 2019.

The study was done in compliance with the Code of Ethics [Helsinki Declaration] of the International Medical Association for Human Studies. Besides, an informed consent was signed by the guardian of its participant. The diagnosis of diabetes mellitus type-1 according to criteria for the diagnosis of diabetes obtained from the American Diabetes Association [2018].

Inclusion criteria: All children diagnosed as diabetes mellitus type 1 based upon American diabetic association criteria for diagnosis [9]. Age from 2-15 years. Both sexes were included. All children with a body mass index $<30$. Children with two years or more of diabetes mellitus type 1.

Exclusion criteria: Children who received iron therapy in the last three months, acute and chronic infection, other chronic diseases, hemolytic anemia, hemoglobinopathies, hypothyroidism, abnormal renal function, red cell disorders, observed blood loss, and myelodysplastic syndrome.

All patients included were subjected to complete medical history, complete general examination [body weight in $\mathrm{kg}$ was measured by the scale, height in $\mathrm{cm}$ was measured without shoes, body mass index [BMI] was calculated as weight $[\mathrm{kg}] /$ height $\left[\mathrm{m}^{2}\right]$, the examination of the insulin injection sites, pallor, hand \& nail, tongue and exercise tolerance], complete systemic examination for each patient including [cardio- 
vascular, chest, abdominal, neurological and musculoskeletal system] and the following investigations [CBC, $\mathrm{HbA} 1 \mathrm{c}$, serum iron, serum ferritin, total iron-binding capacity, c-reactive protein [CRP], fasting blood glucose, postprandial blood glucose, and the erythrocyte sedimentation rate [ESR]].

Specimen collection: Under complete aseptic technique, $8 \mathrm{ml}$ of peripheral venous blood was collected and added to 4 tubes. The first tube; contain EDTA for glycated hemoglobin level and complete blood count. The second tube; contain Fluoride for estimation of blood glucose level. The third tube; contain buffer Sodium Citrate to estimate erythrocyte sedimentation rate. The fourth tube; allowed to dry and centrifuged to produce serum for Serum C-reactive protein [CRP], Ferritin, Total Iron Binding Capacity, and Iron.

The blood was collected into a dry clean centrifuge tube to obtain serum and left to be clotted. It was set in a centrifuge at a 4500 rate per minute [r.p.m] for 10 minutes. Serum samples were kept frozen at -20 until analyses were performed, repeated freezing of samples was avoided.

The blood glucose level was determined by the enzymatic colorimetric method[10]. Hemoglobin A1C was performed on Roche/ COBAS INTEGRA® 400 plus analyzer- Diagnostics Roche, Roche Diagnostic, Germany, using kits supplied by Roche Diagnostic, Germany. Patients were considered to be on optimal glycemic control if HBA1C was $<7.6 \%$, suboptimal if it was $7.6-9 \%$, poor if it was $>9$ percentage [11].

Complete blood count [CBC] was done on EDTA-anti-coagulated blood samples using a coulter MAXM [Coulter Corporation] based on the manufacturer's instructions [12]. Serum ferritin was estimated by chemiluminescence immunoassay [Advia Centaur CP, Siemens, Switzerland, and the USA ${ }^{[13]}$. Serum iron and TIBC were determined by ADVIA 1800 Chemistry and ADVIA Chemistry XPT analyzers ${ }^{[14]}$. Serum C-reactive protein [CRP] performed on Roche/ COBAS INTEGRA® 400 plus analyzer-Diagnostics Roche, Roche Diagnostic, Germany using kits supplied by Roche Diagnostic, Germany[15]. Erythrocyte sedimentation rate: Made by ordinary manual Westergren technique ${ }^{[16]}$.
Statistical Analysis: Our data was entered and processed on a computer using a statistical package for social science [version 24]. Our results were viewed in tables and figures then interpreted. Mean, frequency, range, standard deviation, and percentage used as descriptive statistics. Chi-Square test $\left[\mathrm{X}^{2}\right]$ was used to evaluate the association variables for data. A student's $t$-test was applied for comparison between two groups. ANOVA [F test] applied to normally quantitative variables to compare more than two groups. P-value was considered significant $P>0.05$ : Non significant, $P \leq 0.05$ : Significant [17].

\section{RESULTS}

The mean $\mathrm{HbA} 1 \mathrm{c}$ values of the iron-deficient diabetic group in optimal glycemic control, suboptimal glycemic control, and poor glycemic control level were $[7.3 \pm 0.15] \%$, [8.8 \pm 0.16$] \%$ and $[14.1 \pm 1.3] \%$ respectively. The mean $\mathrm{HbA} 1 \mathrm{c}$ values of iron sufficient diabetic group in optimal glycemic control, suboptimal glycemic control, and poor glycemic control level were [5.9 \pm 0.4$] \%,[7.9 \pm$ $0.3] \%$ and $[10.5 \pm 1.3] \%$ respectively. Also, there was a highly significant increase in the $\mathrm{HbA} 1 \mathrm{c}$ value of the iron-deficient diabetic group compared to iron sufficient diabetic group at all levels of glycemic control [P-value <0.001] Table [1]. There was no statistically significant difference between the irondeficient diabetic group and iron sufficient diabetic group regarding general characteristics [age Pvalue $=0.27$, [weight $P$-value $=0.24$, [gender $P$ value $=0.72$ ], and [family history of diabetes $P$-value $=0.45]$ ] [Table 2].

Regarding the pallor and CNS symptoms [irritability, attention deficit, and restless leg syndrome], there were highly significant increases in the iron-deficient diabetic group in compared to the iron sufficient diabetic group as [ $\mathrm{P}$-value $<0.001$ ] [Table 3].

Regarding fasting blood glucose and postprandial blood glucose, there were no statically significant differences between the iron-deficient diabetic group and the iron sufficient diabetic group[[Fasting blood glucose P-value $=0.078]$ and [Post prandial blood glucose P-value $=0.18$ ] [Table 4]. 
Regarding the number of diabetic patients with iron deficiency anemia, there were 21 patients

[26.3\%] and 59 diabetic patients [73.7\%] in iron sufficient state [Table 5].

Table [1]: Comparison between the iron deficient group and iron sufficient group as regard $\mathrm{HbA} 1 \mathrm{C}$

\begin{tabular}{|c|c|c|c|c|c|c|}
\hline \multicolumn{3}{|c|}{ Variable } & $\begin{array}{c}\text { Iron deficient } \\
{[\mathrm{n}=21]}\end{array}$ & $\begin{array}{c}\text { Iron sufficient } \\
{[\mathrm{n}=59]}\end{array}$ & t-test & P-value \\
\hline \multirow{2}{*}{$\begin{array}{c}\mathrm{HbA1c} \\
\text { percent }\end{array}$} & $<7.6$ & Mean \pm SD & $7.3 \pm 0.15$ & $5.9 \pm 0.4$ & 8.9 & $0.001^{*}$ \\
\cline { 2 - 8 } & $7.6-9.0$ & Mean \pm SD & $8.8 \pm 0.16$ & $7.9 \pm 0.3$ & 5.5 & $0.001^{*}$ \\
\cline { 2 - 8 } & $>9.0$ & Mean \pm SD & $14.1 \pm 1.3$ & $10.5 \pm 1.3$ & 7.3 & $0.001^{*}$ \\
\hline
\end{tabular}

Values present as mean + SD \& analyzed by Independent samples t-test. *: Significant. HbA1c: hemoglobin A1c

Table [2]: Comparison between Iron deficient group and Iron sufficient group as regards general characteristics

\begin{tabular}{|l|l|c|c|c|}
\hline \multicolumn{2}{|c|}{ Variable } & $\begin{array}{c}\text { Iron deficient } \\
{[n=21]}\end{array}$ & $\begin{array}{c}\text { Iron sufficient } \\
{[n=59]}\end{array}$ \\
\hline \multirow{3}{*}{ Age [years] } & Range & $4-14$ & $3-15$ & 0.27 \\
\cline { 2 - 5 } & Mean \pm SD & $9.4 \pm 3.4$ & $8.3 \pm 3.8$ & 0.72 \\
\hline \multirow{2}{*}{ Gender ${ }^{1}$} & Male & $9[42.8 \%]$ & $28[47.4 \%]$ & $31[52.5 \%]$ \\
\cline { 2 - 5 } & Female & $12[57.1 \%]$ & $32[54.2 \%]$ & 0.45 \\
\hline Family history of DM ${ }^{1}$ & Negative & $13[61.9 \%]$ & $27[45.7 \%]$ & $24.6 \pm 7.6$ \\
\cline { 2 - 5 } & Positive & $8[38.1 \%]$ & $26.8 \pm 7.2$ & 0.24 \\
\hline
\end{tabular}

Values present as mean + SD \& analyzed by Independent samples t-test; ${ }^{1}$ Values present as the number and percent \& analyzed by Chi-square test

Table [3]: Distribution of Pallor and CNS symptoms among the studied sample

\begin{tabular}{|c|c|c|c|c|c|}
\hline \multicolumn{3}{|c|}{ Variable } & $\begin{array}{l}\text { Iron deficient } \\
{[n=21]}\end{array}$ & $\begin{array}{l}\text { Iron sufficient } \\
{[n=59]}\end{array}$ & $P$ \\
\hline \multirow{2}{*}{\multicolumn{2}{|c|}{ Pallor }} & Negative & $15[71.4 \%]$ & 59 [100.0\%] & \multirow[t]{2}{*}{$0.001^{*}$} \\
\hline & & Positive & $6[28.5 \%]$ & $0[0.0 \%]$ & \\
\hline \multirow[t]{6}{*}{ CNS symptoms } & \multirow[t]{2}{*}{ Irritability } & Negative & $14[66.7 \%]$ & 59 [100.0\%] & \multirow[t]{2}{*}{$0.001^{*}$} \\
\hline & & Positive & $7[33.3 \%]$ & $0[0.0 \%]$ & \\
\hline & \multirow[t]{2}{*}{ Attention-deficit } & Negative & $11[52.4 \%]$ & $59[100.0 \%]$ & \multirow[t]{2}{*}{$0.001^{*}$} \\
\hline & & Positive & $10[47.6 \%]$ & $0[0.0 \%]$ & \\
\hline & \multirow[t]{2}{*}{ Restless legs syndrome } & Negative & $15[71.4 \%]$ & 59 [100.0\%] & \multirow[t]{2}{*}{$0.001^{*}$} \\
\hline & & Positive & $6[28.5 \%]$ & $0[0.0 \%]$ & \\
\hline
\end{tabular}

Values present as the number and percent \& analyzed by Chi-square test; *: Significant

Table [4]: Comparison between Iron deficient group and Iron sufficient group as regard Fasting Blood Glucose [FBG] and Post Prandial Blood Glucose [PPBG]

\begin{tabular}{|c|c|c|c|c|c|}
\hline \multicolumn{2}{|c|}{ Variable } & $\begin{array}{c}\text { Iron deficient } \\
{[\mathrm{n}=21]}\end{array}$ & $\begin{array}{c}\text { Iron sufficient } \\
{[\mathrm{n}=59]}\end{array}$ & t-test & P-value \\
\hline FBG $[\mathrm{mg} / \mathrm{dL}]$ & Mean \pm SD & $141.2 \pm 90.1$ & $188.7 \pm 108.9$ & 1.8 & 0.078 \\
\hline PPBG $[\mathrm{mg} / \mathrm{dL}]$ & Mean \pm SD & $310 \pm 116.9$ & $350 \pm 118.5$ & 1.3 & 0.18 \\
\hline
\end{tabular}

Values present as mean + SD \& analyzed by Independent samples t-test; FBG: fasting blood glucose; PPBG: postprandial blood glucose

Table [5]: Distribution of iron deficiency anemia among diabetic children

\begin{tabular}{|c|c|c|}
\hline Variable & Diabetic Iron Deficient & Diabetic Iron Sufficient \\
\hline Number of patients[80] & $21[26.3 \%]$ & $59[73.7 \%]$ \\
\hline
\end{tabular}




\section{DISCUSSION}

Diabetes mellitus type 1 is considered to be the most life-threatening endocrine disorder in children[18].

It is a chronic disease related to the immunological condition in which there is the damage of $\beta$ cells of Langerhans that produce insulin hormone in the pancreas. Standardized data revealed that the incidence of type 1 diabetes mellitus had been elevated 3-4\% over the past 30 years, and this result supports the environmental factors as the risk for the disease [19].

The percentage of IDA cases among anemia cases is about $30 \%$. Also, IDA is considered the commonest type of anemia and is a dangerous public health problem, especially in developing countries. The typical symptoms and signs of IDA are growth retardation, pica, tachycardia, and fatigue. The decrease in cognitive development in children and infants and impairment of the nervous system may be a result of severe IDA [20].

$\mathrm{HbA1C}$ is the standard test for the diagnosis of DM and monitoring of plasma glucose levels on long-term, [21] false decrease or elevation of $\mathrm{HbA} 1 \mathrm{c}$ values may be caused by anemia that may lead to the wrong interpretation of the disease condition. Thus, the level of $\mathrm{Hb}$ is very important in monitoring of $\mathrm{HbA} 1 \mathrm{c}$, and the standard cut-off value of hemoglobin below which $\mathrm{HbA} 1 \mathrm{c}$ cannot be used as an important diagnostic and follow-up tools in diabetes is still controversial[22].

The purpose of this study, which was conducted on 80 diabetic children with type-1 [divided into two groups, 21 diabetic children with iron deficiency anemia and 59 diabetic children with iron sufficient state], was to determine the effects of iron deficiency anemia on hemoglobin A1c in type1 diabetes mellitus.

In our study, we found that in optimal glycemic control, the mean of $\mathrm{HbA} 1 \mathrm{c}$ shows statically highly

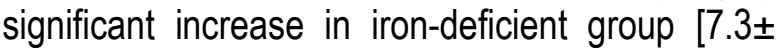
$0.15] \%$ in compared to iron sufficient group [5.9 \pm $0.4] \%$, as [p value $<0.001$ ], also in case of suboptimal glycemic control the mean of $\mathrm{HbA} 1 \mathrm{c}$ shows statically highly significant increase in irondeficient group $[8.8 \pm 0.16] \%$ in compared to iron sufficient group $[7.9 \pm 0.3] \%$, as [p value $<0.001]$. In poor glycemic control, the mean of $\mathrm{HbA} 1 \mathrm{c}$ shows a statically highly significant increase in the irondeficient group [14.1 \pm 1.3$]$ when compared to the iron sufficient group [10.5 \pm 1.3$] \%$, as [p value < 0.001 ]. So $\mathrm{HbA} 1 \mathrm{c}$ shows a highly significant increase in the iron-deficient compared to the iron sufficient group in all degrees of glycemic control.

The possible causes of elevation of $\mathrm{HbA} 1 \mathrm{c}$ in iron deficiency anemia may be due to many reasons as the renewal of red blood corpuscle, the change in conformation of hemoglobin, and the rate of glycation. All previous factors cause significant changes in the formation of $\mathrm{HbA} 1 \mathrm{c}$. The production rate of $\mathrm{HbA} 1 \mathrm{c}$ is usually related to plasma glucose levels, and the rate of RBCs turnover influences the $\mathrm{HbA} 1 \mathrm{c}$ level. The presence of circulating RBCs for a longer time in the plasma may lead to an increase of its glycation[23].

Also, iron deficiency stimulates glycation of terminal proline by modulating the hemoglobin structure while decreasing the RBCs turnover rate. From a pathogenesis perspective for diabetes, deficiency of iron stimulates glycation by peroxidation as deficiency of iron may reduce the activity of enzymes that contain iron, which leads to decrease antioxidant capacity. [22].

In addition, the possible cause of increased $\mathrm{HbA}$ 1c level in IDA may be demonstrated by theory stated that if serum glucose still constant, an increase in the glycated fraction of hemoglobin might be due to decrease in the hemoglobin concentration [24].

Although there are multiple studies on the effect of IDA on $\mathrm{HbA} 1 \mathrm{c}$ level in the diabetic patient in adults, studies are very limited in the pediatrics field. So in line with our result, a survey by Urrechagaa[24] cross-sectional was done on 661 diabetic patients divided into three groups depending on the iron state to normal iron level, latent iron deficiency, and iron-deficiency anemia. The result was a significant increase in the $\mathrm{HbA1c}$ levels in both latent iron deficiency and IDA in both males and females irrespective of fasting plasma glucose. 
Also, our study supported by Christy et al. [25] a case-control study was conducted on 120 diabetic iron-deficient anemic patients with optimal glycemic control and 120 iron-sufficient non-anemic individuals as a control found a significant increase in $\mathrm{HbA} 1 \mathrm{C}$ in the IDA group [6.8 $\pm 1.4 \%$ ] compared to control $[5.65 \pm 0.69]$.

Also, our results agree with Tarim et al.[26], that is conducted on 37 diabetic children type-1 divided into 11 iron-deficient group, and 26 were an iron-sufficient group. They concluded that in type 1 DM patients having a similar level of glycemia, iron deficiency anemia is accompanied by increase $\mathrm{HbA1c}$ levels.

Also, our results are consistent with Salah et al.[27] that is done on 200 children having diabetes mellitus type- 1 visiting the diabetic clinic of pediatric in Cairo, Egypt scanned for anemia and other diabetic complications. And the result stated that $\mathrm{HbA1c}$ levels show a statistically significant increase in diabetic iron-deficient more than in diabetic non-iron-deficient patients $[P<0.01]$.

In contrary to our study, there is Akkermans et al. [28], which was a prospective study done in the Netherlands in the period from Jan 2015 to Sep 2016, on 227 diabetic children patients, divided into absolute ID functional ID, and non-iron deficient.

They concluded that patients with absolute ID and functional ID had similar $\mathrm{HbA} 1 \mathrm{c}$ values as patients with a normal iron level, while iron therapy in absolute ID did not significantly change their $\mathrm{HbA} 1 \mathrm{c}$ values. Our results are different from this study may be due to heterogeneous study designs, Egyptian diabetic children with a higher overall risk for ID and our study did not differentiate between absolute ID and functional ID.

In contrary to our study there is Solomon et al. [29], which was a cross-sectional study done on 174 diabetic patients [87 have iron deficiency anemia and 87 with normal CBC] from Apr to Jul 2016, that concluded $\mathrm{HbA} 1 \mathrm{c}$ level is significantly decreased in diabetic patients with iron deficiency anemia compared to the non-iron deficiency anemia diabetic patients. The difference in our result and Solomon et al. result may be due to more than one factor as our result only on type 1 diabetic children aged from 2 - 15 years, and Solomon et al. study on adults their mean age was [ $47.5 \pm 15.83$ ] years and did not determine the type of diabetes.

In our study, the prevalence of iron deficiency anemia in diabetic children type 1 was 21 children [26.3\%], from a total of 80 children diabetics, this result in line with Wójciak et al. [30], that found newly diagnosed diabetic children type 1 have about $26 \%$ iron-deficient anemia.

Also, in line with our study, Salah et al. [27] found that 41 [20.5\%] type 1 diabetic children had microcytic hypochromic iron-deficient anemia of a total of 200 diabetic children.

Also, this result in line Tarim et al. [26] that is conducted on 37 diabetic children type-1, the number of anemic iron deficient diabetic children was 11 children [29.7\%] from total 37 children.

In our study, the mean age of the iron-deficient diabetic group was [9.4 \pm 3.4$]$ years, and the mean age of the iron sufficient diabetic group was [8.3 $\pm 3.8]$ years. There was no significant difference between both groups [P value $=0.27]$. The number of diabetic children who had iron deficiency anemia was 21 patients, 9 of them were males [42.8\%], and 12 patients were females [57.1\%], this result in line with Salah et al. [27] that found 75 patients were anemic [37 males [49.3\%] and 38 females[50.7\%]]. Also, we found no significant difference between the iron-deficient diabetic group and the iron sufficient diabetic group regarding family history of diabetes as $[P$ value $=0.45]$.

In our study, the number of diabetic children who had iron deficiency anemia was 21 patients, only 6 of them had a pallor [28.5\%], and 7 of them had irritability [33.3\%]. Also, there was a highly significant increase in the iron deficiency diabetic group in compared to iron sufficient diabetic group as regard pallor and irritability $[P$ value $<0.001]$.

This result in line with Joo et al. [31], which is done on 1,782 children with iron deficiency anemia aged from 6 months to 18 years who attended to the hospital, Incheon, Korea, the result stated that, only $23.6 \%$ of patients who come to the hospital with iron deficiency anemia symptoms, such as pallor and night irritability from all cases with a confirmed diagnosis of anemia. 
Also our study, the number of diabetic children who had iron deficiency anemia were 21 patients, 10 of them had an attention deficit [47.6\%], and only 6 of them had restless legs syndrome [28.5\%]. Also, there was a highly significant increase in the iron deficiency diabetic group in compared to iron sufficient diabetic group as regard attention deficit and restless legs syndrome [P value $<0.001]$, this result in line with Allen et al. [32], that is conducted on 251 IDA patients the result stated that the occurrence of clinically restless legs syndrome [RLS] was 79 [31.5\%], nine times higher than the general population.

Conclusion: Iron deficiency anemia seems to be a factor that increases $\mathrm{HbA} 1 \mathrm{c}$ levels in children with Type 1 diabetes mellitus, at the same degree of glycemia. The occurrence of iron deficiency anemia in type 1 diabetic children must be considered. Iron deficiency anemia must be corrected before diagnosing or following type-1 diabetic children by using Hemoglobin A1c.

Recommendation: Regular Follow up of CBC and iron profile in children with type 1 diabetes, especially those who use $\mathrm{HbA} 1 \mathrm{c}$ as an indicator for glycemic control. Iron supplementation should be recommended in needed cases. Further studies on a large scale to evaluate the effect of iron deficiency anemia on $\mathrm{HbA} 1 \mathrm{c}$ in diabetic children with type-1.

Financial and Non-financial Relationships and Activities of Interest

None

\section{REFERENCES}

1- Katsarou A, Gudbjörnsdottir S, Rawshani A, Dabelea D, Bonifacio E, Anderson BJ, Lernmark A. Type 1 diabetes mellitus. Nat Rev Dis Primers. 2017; 3[1]: 1-17. doi: 10.1038/ nrdp.2017.16.

2- Bluestone JA, Herold K, Eisenbarth G. Genetics, pathogenesis and clinical interventions in type 1 diabetes. Nature. 2010; 464: 1293-1300. doi: 10.1038 / nature 08933 .

3- Rhee SY, Chon S, Kwon MK Park IB, Ahn KJ, Kim IJ, Baik SH. Prevalence of chronic complications in Korean patients with type 2 diabetes mellitus based on the Korean national diabetes program.
Diabetes Metab J. 2011; 35: 504-512. doi: 10. 4093/d mj.2011. 35.5.504.

4- Sung YA. HbA1c for diagnosis of type 2 diabetes in Korea. Korean J Med. 2011; 80:288-290.

5- Kim C, Bullard KM, Herman WH, Beckles GL. Association between iron deficiency and $\mathrm{A} 1 \mathrm{C}$ levels among adults without diabetes in the National Health and Nutrition Examination Survey, 1999-2006. Diabetes Care. 2010 33[4]: 780-5. doi: 10.2337/dc09-0836.

6- Sinha N, Mishra TK, Singh T, Gupta N. Effect of iron deficiency anemia on hemoglobin A1C levels. Ann Lab Med. 2012; 32[1]:17-22. doi: 10.3343/ alm.2012. 32. 1.17

7- Özdemir N. Iron deficiency anemia from diagnosis to treatment in children. 2015 Turkish Archives of Pediatrics/Türk Pediatri Arşivi, 2015; 50[1]: 1119. doi: 10.5152/tpa.2015.2337.

8- Barbieri J, Fontela PC, Winkelmann ER, Zimmermann CE, Sandri YP, Mallet EK, et al. Anemia in patients with Type 2 diabetes mellitus. Anemia. 2015; 354737. doi: 10.1155/2015/ 354737.

9- American Diabetes Association. Classification and diagnosis of diabetes: standards of medical care in diabetes 2018. Diabetes care. 2018; 41[1]: S13-27. doi. 10.2337/dc18-S002

10-Burtis C, Ashwood E, Bruns D. Tietz NW, Tietz text book of clinical chemistry, WB Saunders. Co. London, Phuladelphia. 2012; 796[5]:45-49.

11-International Society for pediatric and Adolescent Diabetes. ISPAD consensus Guidelines for the management of type $1 \mathrm{DM}$ in children and adolescent, Published by Medical Forum International 2000; 11-101.

12- Borelli $P$, Blatt $S$, Pereira J, de Maurino BB, Tsujita M, de Souza AC, Fock RA. Reduction of erythroid progenitors in protein-energy malnutrition. Br J Nutr. 2007; 97[2]: 307-314. doi: 10.1017/S0007 114507172731

13- Dupuy AM, Debarge L, Poulain M, Badiou S, Rossi M, Cristol JP. Determination of serum ferritin using immunoturbidimetry or chemiluminescent detection in comparison with radioimmunoassay a compendium of a methodlogical juxtaposition. Clin Lab. 2009; 55 [5-6]: 207-215. PMID: 19728554 
14- Tahmasebi H, Higgins V, Woroch A, Asgari S, Adeli K. Pediatric reference intervals for clinical chemistry assays on Siemens ADVIA XPT/1800 and Dimension EXL in the CALIPER cohort of healthy children and adolescents. Clin Chim Acta. 2019; 490: 88-97. doi: 10.1016/j.cca. 2018.12.011.

15- Sanchez A, Mirabel JL, Barrenechea E, Eugui J, Puelles A, Castaneda A. Evaluation of an improved immunoturbidimetic assay for serum $\mathrm{C}$ reactive protein on a COBAS INTEGRA 400 Analyzer. Clin Lab. 2002; 48[5-6]: 313-317. PMID: 12071582

16-Gilmour D, Sykes AJ. Westergren and Wintrobe methods of estimating ESR compared. $\mathrm{Br}$ med J. 1951; 2[4746]: 1496. doi: 10.1136/bmj.2. 4746.1496 .

17- Levesque R. SPSS Programming and Data Management: A Guide for SPSS and SAS Users, SPSS Inc. 2005; Chicago III. PDF ISBN, 156827-390-8.

18-Gregg EW, Bracco P. The Dynamics of Diabetes Prevalence, Morbidity, and Mortality. In: Rodriguez-Saldana J. [eds] The Diabetes Textbook. 2019; 3:11-21. Springer, Cham.

19-Norris JM, Johnson RK, Stene LC. Type 1 diabetes-early life origins and changing epidemiology. Lancet Diabetes Endocrinol. 2020; 8 [3]: 226-238. doi: 10. 1016/S2213-8587[19] 30412-7.

20-Soliman AT, De Sanctis V, Yassin M, Soliman N. Iron deficiency anemia and glucose metabolism. Acta Bio Medica: Atenei Parmensis 2017; 88[1]: 112-8. doi: 10. 23750/ abm.v88i1.604.

21-Florkowski C. HbA1C as a diagnostic test for diabetes mellitus-reviewing the evidence. Clin Biochem Rev. 2013; 34[2]: 75. PMID: 24151343.

22-Guo W, Zhou Q, Jia Y, Xu J. Increased Levels of Glycated Hemoglobin A1c and Iron Deficiency Anemia: A Review. Medical science monitor. Int Med J Exp Clin Res 2019; 25: 8371. doi: 10.12659/ MSM. 916719.

23-Simmons D, Hlaing T. Interpretation of HbA1c: association with mean cell volume and haemoglobin concentration. Diabet Med. 2014; 31[11]: 1387-92. doi: 10.1111/dme.12518.
24-Urrechaga $\mathrm{E}$. Influence of iron deficiency on $\mathrm{Hb} \mathrm{A} 1 \mathrm{c}$ levels in type 2 diabetic patients. Diabetes Metab Syndr: Clin Res \& Rev. 2018; 12[6]: 1051-1055. doi: 10.1016/ j.dsx. 2018.06.024.

25-Christy AL, Manjrekar PA, Babu RP, Hegde A, MS R. Influence of iron deficiency anemia on hemoglobin A1c levels in diabetic individuals with controlled plasma glucose levels. Iran Biomed J. 2014; 18[2]: 88-93. doi: 10.6091/ibj.1257.2014.

26-Tarim ÖM, Küçükerdogan AY, Günay ÜN, Eralp ÖZ, Ercan İ. Effects of iron deficiency anemia on hemoglobin A1C in type 1 diabetes mellitus. Pediatr Int. 1999; 41[4]: 357-362. doi: 10.1046/j.1442-200x. 1999. 01083.x.

27-Salah N, Abdel HF, Abdel GS, El Sayem M. Prevalence and type of anaemia in young Egyptian patients with type 1 diabetes mellitus. East Mediterr Health J. 2005; 11 [5-6]: 959-967. PMID: 16761666

28-Akkermans MD, Houdijk EM, Bakker B, Clementde Boers A, van der Kaay DC, de Vries MC, Brus $F$. Iron status and its association with $\mathrm{HbA1c}$ levels in Dutch children with diabetes mellitus type 1. Eur J Pediatr. 2018; 177[4]: 603610. doi: $10.1007 / \mathrm{s} 00431-018-3104-3$.

29- Solomon A, Hussein M, Negash M, Ahmed A, Bekele $F$, Kahase D. Effect of iron deficiency anemia on $\mathrm{HbA} 1 \mathrm{c}$ in diabetic patients at Tikur Anbessa specialized teaching hospital, Addis Ababa Ethiopia. BMC hematology, 2019; 19 [1]: 2. doi: $10.1186 / \mathrm{s} 12878-018-0132-1$

30-Wójciak RW, Mojs E, Stanisławska-Kubiak M. The occurrence of iron-deficiency anemia in children with type 1 diabetes. J Investig Med. 2014; 62[6], 865-867. doi: 10.1097/JIM.0000000000000098.

31- Joo EY, Kim KY, Kim DH, Lee JE, Kim SK. Iron deficiency anemia in infants and toddlers. Blood Res. 2016; 51[4], 268-273. doi: 10.5045/ br. 2016.51.4.268.

32- Allen RP, Auerbach S, Bahrain H, Auerbach M, Earley CJ. The prevalence and impact of restless legs syndrome on patients with iron deficiency anemia. Am J Hematol. 2013; 88[4], 261-264. doi: 10. 1002/ ajh.23397. 


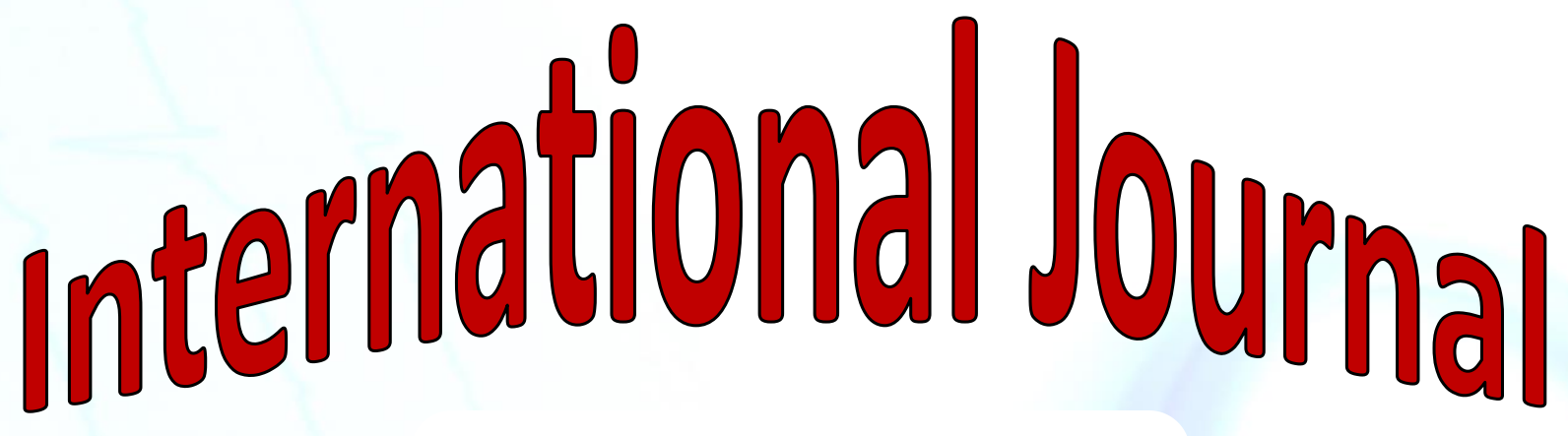

https://ijma.journals.ekb.eg/

Print ISSN: 2636-4174

Online ISSN: 2682-3780

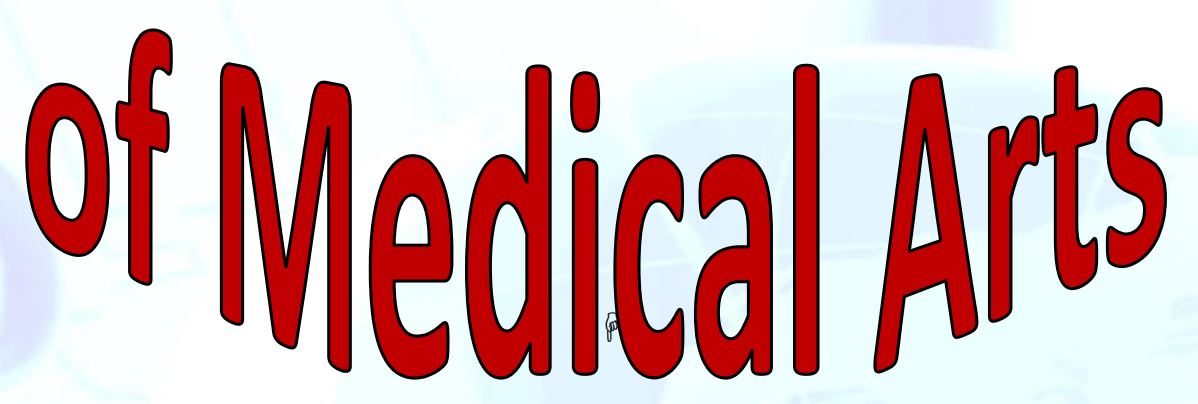

